\title{
EVIDENCE REQUIRED BY HEALTH TECHNOLOGY ASSESSMENT AND REIMBURSEMENT BODIES EVALUATING DIAGNOSTIC OR PROGNOSTIC ALGORITHMS THAT INCLUDE OMICS DATA - ERRATUM
}

\author{
Alexandre Barna \\ Teresita Cruz-Sanchez \\ Karen Berg Brigham
}

\author{
Cong-Tri Thuong \\ Finn Boerlum Kristensen \\ Isabelle Durand-Zaleski
}

doi:10.1017/S026646231800048X. Published online by Cambridge University Press, 23 August 2018

Keywords: Biomarkers, Assessment and regulation, Reimbursement policy, Personalized medicine

Due to an error introduced during copyediting, the title of the publication by Barna et al. (2018) contained a typo. The title has since been corrected. The publisher apologizes for this error.
REFERENCE

1. Barna A, et al. Evidence required by health technology assessment and reimbursement bodies evaluating diagnostic or prognostic algorithms that include omics data. International Journal of Technology Assessment in Health Care. 2018;34:368-377 doi: 10.1017/S026646231800048X. 